\title{
Professores indígenas e não indígenas em formação continuada: conexões e diálogos no Facebook
}

\author{
Indigenous and non indigenous teachers in training: \\ connections and dialogues on Facebook
}

\author{
Rosimeire Martins Régis Santos ${ }^{1}$ \\ Maria Cristina Lima Paniago ${ }^{1}$
}

DOI: http://dx.doi.org/10.20435/tellus.v17i34.456

\begin{abstract}
Resumo: O artigo tem como objetivo refletir e problematizar as conexões e diálogos de professores indígenas e não indígenas, participantes de uma formação continuada em rede social. Os dados apresentados são resultados parciais de uma pesquisa iniciada em $2011^{2}$. Insere-se no Grupo de Pesquisa e Estudos em Tecnologia Educacional e Educação a Distância (GETED)³. Optamos por uma abordagem de pesquisa qualitativa sob a forma de etnografia virtual. Como procedimento metodológico, utilizaram-se depoimentos das interações entre os sujeitos participantes da formação continuada virtual na rede social Facebook. Na tessitura deste artigo, buscamos organizar nossos tateios e experiências em três momentos. Primeiramente, trazemos à reflexão fundamentos teóricos sobre a formação continuada intercultural e suas contribuições para a educação. No segundo momento, mergulhando nas vozes dos professores parceiros da pesquisa, tecemos as conexões e diálogos no Facebook, apresentando os seus anseios, problemas, necessidades e possibilidades, apropriando-nos de conhecimentos ricos e plenos de sentidos para a nossa própria atuação como professoras universitárias e pesquisadoras, possibilitando novas significações para formação e atuação profissional. Por fim, de maneira (in)conclusa, destacamos algumas perspectivas e desafios em relação à formação de professores,
\end{abstract}

\footnotetext{
${ }^{1}$ Universidade Católica Dom Bosco, Campo Grande, Mato Grosso do Sul, Brasil.

${ }^{2}$ A pesquisa é parte do projeto: Formação tecnológica continuada de professores indígenas e não-indígenas em comunidade virtual e multicultural: interconectividade e colaboração. Aprovado pelo edital chamada FUNDECT/CNPq N05/2011 - PPP.

${ }^{3}$ Vale ressaltar que o grupo GETED (Grupo de Pesquisa e Estudos em Tecnologia Educacional e Educação a Distância) tem parcerias de colaboração científica com os pesquisadores de algumas Instituições Nacional e Internacional: Universidade Aberta de Portugal; Universidade de Manitoba - Winnipeg, Canadá (Human Ecology), Universidade Federal de Alagoas (Programa de Pós-Graduação em Letras), Instituto Federal de Educação, Ciência e Tecnologia de Mato Grosso do Sul (IFMS)- Campus Campo Grande, fato este que possibilita uma socialização das experiências em âmbito micro e macro, promovendo a colaboração científica.
} 
a partir do diálogo e das conexões. Alguns resultados da pesquisa apontam que o uso de redes sociais, como espaço de encontro, pode somar-se à formação continuada de professores, no sentido de ampliar as relações entre grupos e oportunizar aprendizagens. Defendemos uma formação continuada intercultural alicerçada nas necessidades dos docentes, respeitando diferentes maneiras de viver e pensar. O reconhecimento da importância da escuta e do diálogo no sentido de compreender seu(s) significado(s) e sentido(s) em uma determinada cultura é condição importante para avançar na busca de práticas educativas interculturais na formação continuada de professores.

Palavras-chave: diálogo; interculturalidade; formação continuada de professores; Facebook.

Abstract: The article has the objective of reflecting and problematizing the connections and dialogues of Indigenous and Non-Indigenous teachers, participants of a continued formation in social network. The presented data are partial results from research, which started in 2011. It is inserted in the Group of Research and Studies on Educational Technology and Distance Education (GETED). We chose the qualitative research approach under the form of virtual etnography. As a methodological procedure, we used the emerged dialogues in the interactions among the participants of the continued formation in the social network Facebook. Writing this article, we tried to organize our gropings and experiences in three moments. First, we brought the theoretical foundations about intercultural continued formation and the contributions to education. Second, deepening to the teachers'voices, partners of the research, we wove connections and dialogues in Facebook, presenting their wishes, problems, necessities and possibilities, appropriating rich and plenty of meanings knowledge to our own practice of teaching and researching, opening possibilities of new significances of formation and professional actions. At last, in an unfinished way, we draw attention to some perspectives and challenges in relation to the teachers' formation, from some dialogues and connections. Some results of the research show that the use of the social networks, as space of meetings, can be added to the continued teachers formation in the sense of enlarging the relations among groups and of giving opportunity to learning. We stand up for an intercultural continued formation based on the teachers'necessities, respecting their ways of diferent living and thinking. The recognition of the importance of listening and of the dialogue in the sense of understand meanings and senses in a determined culture is an important condition to go forward in searching intercultural educational practices in teachers continued formation.

Key words: dialogue; interculturality; continued teachers formation; Facebook. 


\section{INTRODUÇÃO}

Este artigo originou-se de uma pesquisa intitulada "Formação tecnológica continuada de professores indígenas e não-indígenas em comunidade virtual e multicultural: interconectividade e colaboração". Tal formação iniciou-se a partir de um desabafo de uma professora indígena terena sobre a falta de espaços de discussão relacionada às tecnologias no contexto educacional.

Os participantes da formação são professores e alunos pesquisadores de uma Universidade privada do Estado de Mato Grosso do Sul e professores de uma escola indígena do distrito de Taunay, município de Aquidauana, em Mato Grosso do Sul.

Em 2012, criamos um grupo na rede social Facebook ${ }^{4}$ denominado "Formação continuada tecnológica: Linguagens, Saberes e Interculturalidade ${ }^{5 "}$, como ambiente de interação para os estudos, compartilhamentos e debates.

A formação continuada no Facebook atende professores indígenas e professores não indígenas e teve, como objetivo, abrir espaço para reconstrução e ressignificação de concepções sobre teorias e práticas docentes relacionadas às tecnologias de informação e comunicação e redes sociais inseridas no contexto educacional.

A formação continuada não teve um currículo fechado, ela desenvolveu-se de acordo com as necessidades e características dos participantes do grupo. O movimento na rede social Facebook definiu caminhos para o grupo seguir, de acordo com as dificuldades e possibilidades que os professores enfrentavam no seu dia a dia com a inserção das tecnologias de informação e comunicação (TIC) no contexto educacional.

Optamos por uma abordagem teórica metodológica de pesquisa qualitativa sob a forma de etnografia virtual, utilizando uma combinação de geração de registros, como captura de diálogos, links, imagens, textos e interações entre os participantes do grupo.

${ }^{4}$ O Facebook foi criado em fevereiro de 2004, por Mark Zuckerberg na Universidade de Harvard. O entendimento construído de rede social aqui vem ancorado em (GARTON; HAYTHORNTHWAITE; WALLMAN, 1997, p. 1) quando este afirma que, "Quando uma rede de computadores conecta uma rede de pessoas e organizações, é uma rede social".

${ }^{5}<$ https://www.facebook.com/groups/Formacaocontinuadatecnologicaintercultural/>. 
Na tessitura deste artigo, buscamos organizar nossos tateios e experiências em três momentos. Primeiramente, trazemos à reflexão fundamentos teóricos sobre a formação continuada intercultural e suas contribuições para a educação. No segundo momento, mergulhando nas vozes dos professores parceiros da pesquisa, tecemos as conexões e diálogos no Facebook, apresentando os seus anseios, problemas, necessidades e possibilidades, apropriando-nos de conhecimentos ricos e plenos de sentidos para a nossa própria atuação como professores universitários e pesquisadores, possibilitando aos nossos parceiros de trabalho novas significações para sua formação e atuação profissional. Por fim, de maneira (in)conclusa, destacamos algumas perspectivas e desafios em relação à formação de professores, a partir do diálogo e das conexões em um espaço de formação continuada que se amplia com seus atores que navegam, que compartilham, que dialogam a partir dos seus saberes.

\section{A ETNOGRAFIA VIRTUAL: METODOLOGIA DE PESQUISA}

Hine (2000), responsável pela popularização do termo, a etnografia virtual, define-a como um termo usado para pesquisar redes sociais on-line estabelecidas em diversos suportes. Vale ressaltar que a mesma autora reforça que a etnografia virtual analisa as práticas sociais na Internet e o sentido destas para os participantes. Ainda Hine (2000) define como base fundamental da etnografia virtual a necessidade de o pesquisador se aprofundar no mundo que estuda por um determinado tempo, entendendo que as relações se formam com quem participa dos processos sociais. Assim, pensamos que a etnografia virtual traz as crenças, práticas, artefatos e conhecimentos compartilhados pela cultura que está sendo estudada.

Para esta pesquisa, nas escolhas realizadas, consideramos os dez princípios propostos por Hine (2000) para uma etnografia virtual que leva em conta a internet como parte de seu campo de conexões. Os dez princípios foram traduzidos por Medrado (2012, p. 45-8), como seguem: o primeiro princípio sugere que a Internet pode ser considerada "[...] como uma forma de comunicar, como um objeto inserido na vida das pessoas e como um ambiente onde uma formação com características de comunidade é constituída e sustentada pelas maneiras como é usada, interpretada e reinterpretada" (HINE, 2000, p. 64); o segundo 
princípio é de que "[...] as mídias interativas, tais como a Internet, podem ser entendidas como cultura ou como artefato cultural. Concentrar em um aspecto e excluir o outro leva a um empobrecimento da percepção" (HINE, 2000, p. 64); o terceiro princípio considera o campo como conexões e afirma que "podemos nos beneficiar pensando a etnografia das interações mediadas como móvel ao invés de multilocada" (HINE, 2000, p. 64); o quarto princípio afirma que "o objeto da pesquisa etnográfica pode ser beneficiado por uma reformulação do seu princípio organizador em favor do fluxo e da conectividade ao invés do lugar e suas fronteiras" (HINE, 2000, p. 64); o quinto princípio trata da delimitação do estudo como algo fluido, já que "o próprio objeto etnográfico pode ser reformulado a cada decisão de seguir outra conexão ou retroceder a um ponto anterior" (HINE, 2000, p. 64), dessa forma, na fluidez de conexões e possibilidades, "encerrar a etnografia transforma-se em uma decisão pragmática" (HINE, 2000, p. 64); o sexto princípio leva em conta as múltiplas temporalidades da vida quando afirma que "a etnografia virtual é intersticial, já que ela se ajusta às outras atividades de ambos: etnógrafo e sujeito. A imersão no cenário só é alcançada de forma intermitente" (HINE, 2000, p. 65); o sétimo princípio considera que a "etnografia virtual é necessariamente parcial. Uma descrição holística do informante, do local ou da cultura é impossível de ser alcançada" (HINE, 2000, p. 65); o oitavo princípio afirma que "a forma de interação com os participantes por meio da tecnologia são parte da etnografia, assim como as interações do etnógrafo com a tecnologia" (HINE, 2000, p. 65); o nono princípio destaca que "todas as formas de interação são etnograficamente válidas, não apenas a face a face" (HINE, 2000, p. 65); e, o décimo princípio localiza a etnografia virtual como uma "etnografia adaptada que se configura para adequar-se às condições em que se encontra" (HINE, 2000, p. 65).

Entendemos a etnografia virtual como uma forma do fazer etnográfico nos espaços virtuais suportados pela Internet. Essa metodologia de pesquisa pode ser utilizada para explorar as complexas relações existentes entre as pessoas e as tecnologias, e nos mais diferentes espaços sociais, tais como: residências, local de trabalho, mídia de massa, redes sociais na internet, bem como ambientes educacionais e acadêmicos. Paniago, Santos e Godoi (2016, p. 392), destacam que:

a presença do eu atrelado em conversação nas redes sociais virtuais, muitas vezes, dá forma e conteúdos às manifestações coletivas complementadas por comentários, imagens, textos, vídeos, poesias. 
Cada interação na rede deixa traços, características, registros e gera conteúdos importantes a serem estudados.

Nesse sentido, a formação de professores na rede social Facebook, possibilita uma ação nas interações, fortalecendo comentários, opiniões e consequentemente fotalecendo as relações afetivas daqueles que estão no espaço virtual e participam do processo, compartilhando saberes, trocando experiências e aprendendo. Além disso, como destacam Recuero (2009), essas redes modificam-se em relação ao tempo, pois envolvem características como colaboração, conflito, o que influencia as ações dos sujeitos que se utilizam delas para comunicação, difundindo-se, assim, informações distintas. No entanto a formação continuada no Facebook desenvolve-se conforme as interações que acontecem no coletivo, a partir de informações ou de situações compartilhadas.

\section{O FACEBOOK NO CONTEXTO DA FORMAÇÃO CONTINUADA DE PROFESSORES}

Mas o que é o Facebook?

O Facebook é uma rede social gratuita, que foi criada em 2004 por um grupo de quatro estudantes da Universidade de Harvard, com o objetivo de ser um espaço no qual as pessoas se encontrassem, compartilhassem opiniões e fotografias visando, no início, criar uma rede de comunicação apenas para os estudantes da própria Universidade. Todavia, em poucos meses, a rede expandiu-se entre as universidades americanas, conectando jovens de mais de 800 instituições (ARRINGTON, 2005). A sua popularidade cresceu e, em menos de um ano, já tinha 1 milhão de utilizadores ativos. A rede social possibilita o indivíduo criar um perfil pessoal, ao qual são disponibilizados campos para diferentes informações, como "sobre você" permite ao utilizador realizar uma autodescrição, data de nascimento, trabalho e educação, relacionamento, cidade onde mora etc.

Cada pessoa que possui o perfil é livre para partilhar fotos, vídeos, mensagens, textos e outros. No Facebook, também, é permitido criar grupos fechados que funcionam como uma sala virtual privada, onde os membros podem interagir através de mensagens, podem compartilhar vídeos, noticiários, imagens, músicas, arquivos e outros materiais que possibilitam que o conhecimento passa a ser 
compartilhado por meio de conexões de informações. De acordo com Recuero (2009), uma rede social é composta por atores (nós) e suas conexões (interações).

O grupo "Formação Continuada Tecnológica: Linguagens, saberes e interculturalidade", que mantemos no desenvolvimento da formação continuada de professores, é fechado, ou seja, qualquer pessoa pode encontrar o grupo e ver quem está nele. Somente membros podem ver as publicações. Nesse grupo, qualquer membro pode adicionar membros, mas um administrador ou um moderador deve aprová-los. Membros, administradores e moderadores podem publicar no grupo.

As interações que mantemos por meio do grupo na rede social com os professores indígenas e não indígenas criaram naturalmente a ideia de uma formação continuada que ocorre no mundo virtual, paralelo ao mundo físico, no qual mantemos por meio de conexões com a internet, podendo ser acessado de inúmeros equipamentos, como computador, laptops, tablets e telefones celulares.

Diante das interações on-line tecidas com/entre os membros do grupo, uma série de situações se misturam, sem que o ambiente físico desapareça, é o espaço da Universidade, é o espaço da Escola da Aldeia Indígena Bananal, os quais se movimentam nas escritas, nos compartilhamentos, nas escutas que são produzidas por meio de encontros, roda de conversas, palestras, oficinas, cursos, artigos, textos, capítulos de livros, que possibilitam ampliar conhecimentos interconectando saberes a partir de acontecimentos vivenciados nos espaços on-line e nos espaços físicos.

Uma prática que fortalecemos no grupo é compartilhar produções abertas como (livros, apresentações, imagens, pesquisas acadêmicas, cursos, vídeos, sites, tutoriais, repositórios de artefatos digitais), e também divulgar eventos educacionais que poderão contribuir com a formação dos membros do grupo.

Santos e Rossini (2014, p. 107), destacam que:

As redes sociais têm contribuído e ampliado às discussões para além do ciberespaço. A formação de comunidades para discutir temas específicos tem se mostrado profícua quando seus recursos e potencialidades são utilizados de forma proveitosa por seus integrantes.

As curtidas, os comentários, os compartilhamentos no grupo, são narrativas produzidas cheias de sentidos, significados, como afima Lévy (1999, p. 162), 
"as páginas da Web exprimem ideias, desejos, saberes, ofertas de transação de pessoas e grupos humanos". Assim, o espaço de formação continuada na rede social Facebook, possibilita discutir, problematizar, estar junto, contribuir, ampliar discussões de práticas culturais, de saberes, de costumes na construção do conhecimento e na prática profissional dos professores indígenas e não indígenas.

\section{FORMAÇÃO CONTINUADA INTERCULTURAL}

Essa parte do texto apresenta uma reflexão sobre o processo de formação continuada, em que o professor poderá produzir os seus próprios conhecimentos mediante a busca de informações, exigidas com a velocidade das mudanças que vêm ocorrendo no mundo e com o avanço da ciência e da tecnologia. Ou seja, a formação continuada proporciona momentos de diálogos estabelecidos com os professores a partir das necessidades apontadas por eles, na prática diária e na busca de soluções para os problemas enfrentados. Segundo Marcelo García (1999), a formação de professores e professoras:

[...] é a área de conhecimento, investigação e de propostas teóricas e práticas que, no âmbito da didática e da organização escolar, estuda os processos através dos quais os professores - em formação ou em exercício - se implicam individualmente ou equipe, em experiências de aprendizagem através das quais adquirem ou melhoram os seus conhecimentos. [...] e que Ihes permite intervir profissionalmente no desenvolvimento do seu ensino, do currículo e da escola, com o objetivo de melhorar a qualidade da educação que os alunos recebem. (MARCELO GARCÍA, 1999, p. 26).

Alguns autores vêm discutindo a questão da formação de professores (NÓVOA, 1995a ; PACHECO, 1995; GIMENO SACRISTÁN; PÉREZ GOMES, 1998; GARCÍA, 1999; TARDIF; LESSARD, 2005; IMBERNÓN, 2009; 2010). A formação continuada refere-se àquela formação que ocorre quando os professores estão em exercício de sua profissão, após a formação inicial. Essa modalidade de formação pode ser planejada por instituições ou pelos próprios professores, de modo a permitir o desenvolvimento profissional e o aperfeiçoamento do ensino que ministram (GARCÍA, 1999).

A partir desses autores, a formação continuada pode emergir pelos próprios professores, refletindo o exercício da profissão a partir da sua realidade. 
De acordo com Gatti e Barreto (2009), a formação continuada oferecida nas últimas décadas, no Brasil, teve como propósito a atualização e o aprofundamento de conhecimentos profissionais.

Buscamos Candau (2003), que, ao se referir à formação continuada, assim afirma:

A formação continuada não pode ser concebida como um processo de acumulação (de cursos, palestras, seminários etc., de conhecimentos ou de técnicas), mas sim através de um trabalho de reflexividade crítica sobre as práticas e de (re)construção permanente de uma identidade pessoal e profissional, em interação mútua. E é nessa perspectiva que a renovação da formação continuada vem procurando caminhos novos de desenvolvimento. (CANDAU, 2003, p. 64-5).

O nosso foco é buscar caminhos para a formação continuada, como ponto de partida, conhecendo e estabelecendo relações com os participantes a partir de situações culturais que emergem na sala de aula, discutindo assim as possibilidades que são mais adequadas e possíveis a cada contexto.

Segundo Imbernón (2004, p. 15), "[...] a formação assume um papel que transcende o ensino que pretende uma mera atualização científica, pedagógica e didática e se transforma na possibilidade de criar espaços de participação, reflexão e formação [...]".

Assim, a formação para esse grupo de professores nos possibilita problematizar possibilidades de criação de espaços, com participação coletiva e reflexividade, redimensionados pelas Tecnologias de Informação e Comunicação.

Para Nóvoa (1995b), uma formação não se constrói por acumulação, seja ela de cursos, de conhecimentos, de técnicas, mas de um trabalho de reflexão sobre as práticas e da (re)construção permanente de uma identidade pessoal. Acrescenta que o processo de formação alimenta-se de propostas educativas, e que "[...] práticas de formação que tomem como referência as dimensões coletivas contribuem para a emancipação profissional e para a consolidação de uma profissão que é autônoma na produção dos seus saberes e dos seus valores" (NÓVOA, 1995b, p. 27).

Dessa forma, construir práticas de formação continuada intercultural, pensadas no coletivo que considere o contexto dos professores e da escola, constitui um fator relevante nos processos de formação. Ou seja, entendemos 
como formação continuada intercultural estar com, viver com, conviver e ouvir todos e cada um de nós.

Segundo Fleuri (1998), o horizonte da abordagem intercultural é constituído a partir da criação de contextos educativos que oportunizem a integração e a interação criativa, crítica e cooperativa tanto entre os diferentes sujeitos, quanto seus contextos sociais, econômico-políticos e culturais. Portanto, nos processos de aprendizagem e nas relações sociais interculturais, os contatos são de reciprocidade e de trocas, afirma Vieira (1999). Nesse sentido, Coppete, Fleuri e Stoltz (2012, p. 245) destacam que a educação intercultural contempla:

[...] uma abordagem emancipatória e rizomática, constituída na e pela percepção da multiplicidade de olhares, nas inter-relações, na interação entre as diversas culturas. Demanda, indubitavelmente, um encontro. Todavia, não se trata de um encontro pura e simplesmente entre pessoas diferentes. Para que um encontro seja intercultural, na forma como nesta pesquisa se defende e se procura, é significativo que as diferenças sejam como "tensões produtivas", como sugere Torres (1998), de onde se pode partir para a construção de conhecimentos e de práticas escolares e educativas que sejam relevantes para os vários grupos sociais envolvidos.

Outra característica da intercuturalidade é que essa perspectiva entende e considera a relação entre as culturas na prática educativa como modos próprios de cada grupo ver e interagir com a realidade, como argumenta Fleuri (1999).

Concordamos com as ideias destacadas por Torres (1998); Fleuri (1999); Vieira (1999); Coppete, Fleuri e Stoltz (2012), muito especialmente, quando dizem que a educação intercultural se configura como uma relação entre culturas e, muitas vezes, conflituosas, o que implica pensar formas de viver, maneiras de pensar, costumes, histórias de um povo, entre outros, e isso pode ser um indicador de caminhos possíveis, para promover parcerias entre instituições, intercâmbios de estudantes e de pesquisadores para colaborar com a formação continuada intercultural de professores de forma mútua e enriquecedora.

Sob essa ótica, defendemos uma formação continuada intercultural alicerçada nas necessidades dos docentes, respeitando diferentes maneiras de viver e pensar. Segundo Candau (2012, p. 242):

[...] a educação intercultural é concebida hoje como um elemento fundamental na construção de sistemas educativos e sociedades que se 
comprometem com a construção democrática, a equidade e o reconhecimento dos diferentes grupos socioculturais que os integram.

Tendo presente essa realidade, podemos dizer que a interculturalidade está presente nesse grupo de formação continuada, por meio das inter-relações estabelecidas entre professores e alunos pesquisadores de uma Universidade e professores de uma escola indígena, colocando ênfase no reconhecimento da diferença presente na formação continuada, oportunizando espaços em que os saberes diversos possam se expressar como um intercâmbio entre culturas. Como ainda aponta, Candau (2012, p. 247), "[...] é necessário que experimentemos uma intensa interação com diferentes modos de viver e se expressar".

Nessas interações de saberes diversos é que as experiências da formação continuada nos moveram, nos movem a estar e continuar compartihando e somando muitas formas de possibilitar o acesso a conhecimentos que, muitas vezes, vão sendo ressignificados, não porque estavam equivocados, mas, porque foram tensionados pelas interações que nos instigam e convidam a conhecer e aprender outros modos de vida, outros saberes, outras experiências. Como nos propôs Freire (2007, p. 23), "não há docência sem discência". E há reciprocidade nessa relação ao afirmar que "quem ensina aprende ao ensinar e quem aprende ensina ao aprender".

\section{CONEXÕES E DIÁLOGOS NO FACEBOOK: VOZES DE ALGUMAS PROFESSORAS 6}

Segundo Coppete (2012, p. 316), na abordagem de educação intercultural, o diálogo é uma relação que se estabelece horizontalmente entre as pessoas e se concretiza mediante a linguagem, ocupando a centralidade da ação pedagógica, o que demanda respeito, generosidade, amorosidade, humildade, atenção, consideração profunda ao outro, confiança e, substancialmente, reciprocidade; aspectos que também remetem à sensibilidade. O diálogo, em seu conceito mais elevado, é a comunicação mais humana e humanizante (BUBER, 1982; FREIRE, 2000), uma vez que é nele e a partir dele que acontece o máximo de inter-reconhecimento, intersubjetivação e interlocução (MONTEIRO, 1998).

\footnotetext{
${ }^{6}$ Neste artigo, os excertos utilizados foram de professoras apenas, apesar de haver professores homens no grupo. Elas são intituladas com letras no sentido de manter seu anonimato.
} 
Quer dizer, tudo nos leva, pois, a dar novo valor à dimensão cultural da educação e, desse modo, a dar efetivamente a cada um, os meios de compreender o outro, pela escuta na sua especificidade.

De fato, as falas a seguir são reveladoras, ampliando os significados da apropriação do conhecimento, caracterizando igualmente o valor da cultura em sua riqueza.

Com certeza, somos povos diferentes no modo de pensar de agir, de falar de se comunicar com o outro, principalmente no trato. Mas não incapazes pois temos a mesma sabedoria e inteligência da comunidade envolvente, ou seja não índio, pois todos somos criatura criadas pelas mãos Divina."Posso ser tudo que você é sem deixar de ser o que sou". (Professora R).

Nós indígenas vivemos no mundo onde há abundância e fartura, onde tudo que precisamos está lá. O sol radiante que todas as manhãs nos traz a esperança de um novo dia e leva consigo a certeza de ter cumprido o dever, o fogo que siguinifica a paz e a participação de grupos, a semente que embeleza a pele em tempo de festa, e a terra seca que poderá ser replantada. (Professora I).

Desse ponto de vista, concordamos com Brand (2011, p. 208), "os povos indígenas de todo o país são povos com saberes e processos culturais sociais e históricos densamente diferenciados, [...] não se tratam de sujeitos escolares carentes, mas de sujeitos étnicos diferentes". Para o autor, "[...] os saberes tradicionais indígenas estão densamente contextualizados com seu território, com sua relação com a natureza".

As falas e textos das professoras são acessos privilegiados às suas sabedorias, como exemplificado pelas (professoras $\mathrm{R}$ e I), e, refletindo sobre essas questões nessas teias de relações mediada pelas TIC, o conhecimento vem sendo revelado e compreendido nas várias totalidades, com bases em movimentos constantes de interação e colaboração que favorecem a construção de conhecimento. Assim, sugere Giroux (1987, p. 33):

[...] dar a "voz" aos professores. Encará-los como seres pensantes. intelectuais, e não executores. Reconhecer a importância de "valores, ideologias e princípios estruturadores que dão significado às histórias, às culturas e às subjetividades definidoras das atividades diárias dos educadores".

Essas teias de relações mediada pelas TIC, nesse caso, a rede social Facebook, é tecida também com fios afetivos, como esclarece Catapan (2001): 
A rede não se faz apenas de informações. Por trás das informações estão as pessoas que pensam, que sentem, que vibram, que criam, que pulsam. [...] os temas, os objetos, as questões, são lincadas a partir de inúmeros pontos e vão tecendo uma outra forma de conhecer, de pensar, emergir em uma forma de inteligência coletiva que prorifera indefinida e anarquicamente. (CATAPAN, 2001, p. 122).

Como afirma Catapan (2001), percebemos que o uso da rede social para esse grupo de professores em formação traduz em dizer que são pessoas que pensam, problematizam, intervêm, transformam, inventam, produzem, dando sentido, como afirmam Ausubel, Novak e Hanesian (1980), a uma aprendizagem significativa, que se produz quando quem aprende pode estabelecer uma relação substancial entre a novidade, o novo conhecimento e seus conhecimentos prévios, conforme entendimentos manifestados pelas professoras a seguir:

Isso mostra que nós indígenas já estamos inseridos no mundo virtual, e são poucos os que ainda não sabem manuseá-lo. Eu sou uma dessas, mas procurando melhorar. (Professora I).

Isso mostra que como indígena temos que estar inserido na evolução tecnológica sem esquecer nossos valores e cultura. (Professora C).

Bom, para o primeiro momento, eu iria propor uma pesquisa na net sobre outros autores com o mesmo título. Depois pediria que fizessem um desenho no Excel sobre a escola. (Professora I).

É difícil dispensar a tecnologia entre os jovens alunos, acredito que devamos propor atividades onde eles interajam com o mundo tecnológico, onde irão ampliar seus conhecimentos [...]. (Professora B).

O diálogo apresentado com as professoras ( $\mathrm{B}, \mathrm{C}$ e I) em formação, revelam que elas permitem romper as fronteiras tradicionais de ensinar e aprender e combinam, misturam, interconectam nos seus estudos e práticas pedagógicas mediadas pelas TIC, mesmo em situações problemáticas de acesso aos recursos tecnológicos e internet. Segundo a professora A, "[...] os professores indígenas tiveram acesso a uma ferramenta que para alguns até o momento era desconhecida, o notebook, fazendo com que assumam desafios de aprender a manuseá-lo e utilizá-lo na prática pedagógica".

Assim, vamos encontrando na rede social um meio de convivência que pode facilitar o diálogo, ou seja, como destacam Lopes e Santos (2012): 
As TIC e as redes sociais, por meio de suas potencialidades, quando utilizadas de maneira crítica e articulada, podem propiciar novas construções de conhecimento com base nas trocas e partilha de experiências, de concepções, de práticas, de teorias, de ações vivenciadas em diferentes contextos culturais. (LOPES; SANTOS, 2012, p. 162-3).

Na dinâmica da rede social, não há uma receita para preparar e conduzir a formação continuada, é o grupo que ajuda no esclarecimentos de dúvidas, identifica dificuldades, sugere leituras, comunica-se e aprende-se colaborativamente, e isso exige também escutar atentamente o outro, para captar angústias e expectativas. Segundo Boff (2006):

[...] o outro representa sempre um desafio, seja pela estranheza que provoca, seja pelo fato de não ser alguém do nosso mundo, um desafio de compreensão e deciframento. Compreender o outro supõe, na medida do possível, a superação da distância que nos separa dele. Trata-se de estabelecer uma ponte entre dois que se consideram mutuamente diferentes. (BOFF, 2006, p. 29).

Nessa convivência, por meio das conexões na rede, partilhada junto com os outros, participamos de suas vidas, de suas lutas, nas buscas da superação dos problemas postos pela prática. Buscamos outros sentidos de ser os quais envolvem relações humanas, capazes de nos ajudar e ao outro, a se expressar, a negociar ou desenvolver conflitos. É nesse sentido que fortalecemos a nossa trajetória de aprendizagem e de produção de conhecimento, sob uma prática mobilizada pela escuta e diálogo. É exatamente nesse respeito mútuo entre culturas, trocas de saberes por meio do diálogo, que relacionamos a formação como intercultural.

O compartilhar no AVA (ambiente virtual de aprendizagem) é um processo de aprendizado colaborativo, muitas vezes o que compartilhamos promove o choque de ideias entre professores e alunos e, assim, vamos mediando por meio do diálogo, valorizando os saberes de ambos e construindo outros modos de pensar, conhecer, compreender e viver a partir das interações. Segundo Primo:

[...] essa mediação do educador é fundamental para a promoção do debate em torno de questões pertinentes aos temas em desenvolvimento para

intervir com questões que problematizem os textos, exercícios e experiências em estudo e para instigar a capacidade autoral, investigadora e criativa dos educandos. (PRIMO, 2006, p. 42). 
Thompson (2013) nos ajuda a compreender o advento das interações mediadas. O mesmo autor distingue três formas de interação: interação face a face; interação mediada; quase-interação mediada. Ao fazer essa distinção, o autor também explica que seu estudo não sugere que determinadas situações específicas sempre irão coincidir com um dos três tipos de interação. "[...] Pelo contrário, muitas das interações que se desenvolvem no fluxo da vida diária podem envolver uma mistura de diferentes formas de interação - elas têm, em outras palavras, um caráter híbrido" (THOMPSON, 2013, p. 123), como por exemplo o depoimento da Professora (R), "[...] todo mundo tem na vida coisas pra compartilhar e aprender [...] cada momento uma história, uma beleza, um olhar [...]".

Além de essa questão das interações ter um caráter híbrido, Thompson (2013, p. 124) acrescenta que as três formas de interação não se esgotam: "Outras formas de interação podem ser criadas, por exemplo, pelo desenvolvimento de novas tecnologias da comunicação que permitem um maior grau de receptividade".

De acordo com o autor, na maior parte da história humana, a maioria das interações sociais caracterizavam-se como face a face, por meio das tradições orais. Na qual, "[...] Os indivíduos se relacionavam entre si principalmente na aproximação e no intercâmbio de formas simbólicas, ou se ocupavam de outros tipos de ação dentro de um ambiente físico compartilhado" (THOMPSON, 2013, p. 119), como diz a Professora (A), "[...] o compartilhar traz outras pessoas para observar refletir com vc".

O ouvir, alcançado mediante as interações virtuais, ajuda cada integrante perceber o sentido das ações que observa, bem como as significações específicas que o grupo atribui as suas próprias ações, negociações e no intercâmbio de ideias. As interações que se estabelecem entre professores indígenas e não indígenas têm repercussão nas relações entre as pessoas do grupo, proporcionando uma outra forma de conhecer, de olhar, de pensar, ressignificando inúmeros saberes. A formação continuada nesse sentido evolui em um movimento dinâmico de interação entre os professores na rede social, possibilitando uma aprendizagem colaborativa. 


\section{ALGUMAS CONSIDERAÇÕES}

Consideramos que o uso de redes sociais, como espaço de encontro, pode somar-se à formação continuada de professores, no sentido de ampliar as relações entre grupos e oportunizar aprendizagens. O convívio com o grupo de professores indígenas e não indígenas, que possui perspectivas diferenciadas sobre um mesmo assunto e a necessidade permanente de expressar suas opiniões, permite a criação de condições favoráveis para o desenvolvimento do pensamento crítico, da reflexão e da aprendizagem transformadora.

Dessa maneira, todos contribuem para a aprendizagem dos demais e utilizam as TIC e redes sociais como intercâmbio de informações, trocas de ideias e experiências. Essas múltiplas realidades, misturadas de alguma forma, possibilitam os membros do grupo permanecerem em contato e, quando é preciso, colaboram uns com os outros. À distância, permanecem juntos, em colaboração.

O reconhecimento da importância da escuta e do diálogo no sentido de compreender seu(s) significado(s) e sentido(s) em uma determinada cultura é condição importante para avançar na busca de práticas educativas interculturais na formação continuada de professores.

Defendemos uma formação continuada intercultural alicerçada nas necessidades dos docentes, respeitando os diferentes saberes, maneiras de viver e pensar.

\section{REFERÊNCIAS}

ARRINGTON, Michael. 85\% of college students use Facebook. Tech-Crunch, 7 set. 2005. Disponível em: <http://www.techcrunch.com/2005/09/07/85-of-college-students-usefacebook>. Acesso em: 17 fev. 2017.

AUSUBEL, David Paul; NOVAK, Joseph; HANESIAN, Helen. Psicologia Educacional. Rio de Janeiro: Interamericana, 1980.

BOFF, Leonardo. Virtudes para um mundo possível - convivência, respeito e tolerância. Petrópolis, RJ: Vozes, 2006. (v. II).

BRAND, Antonio Jacó. Os acadêmicos indígenas e as lutas por autonomia de seus povos. In: SEMERARO, Giovanni et al. (Org.). Gramsci e os movimentos populares. Niterói: Ed. UFF, 2011. p. 201-14. (v. 1).

BUBER, Martin. Do diálogo e do dialógico. São Paulo: Perspectiva, 1982. 
CANDAU, Vera Maria Ferrão. Diferenças culturais, interculturalidade e educação em direitos humanos. Educação \& Sociedade, Campinas, v. 33, n. 118, p. 235-50, jan./mar. 2012. Disponível em: <http://www.cedes.unicamp.br>. Acesso em: 10 jun. 2016.

. Formação continuada de professores: tendências atuais. In: CANDAU, Vera Maria Ferrão (Org.). Magistério: construção cotidiana. 5. ed. Petrópolis: Vozes. 2003. p. 51-68.

CATAPAN, Araci Hack. O ciberespaço e o novo modo do saber: o retorno a si como um inteiramente outro. In: REUNIÃO ANUAL DA ANPED, 24., Caxambu, 7-11 out. 2001. Anais... Goiânia: Vieira, 2001, p. 117-20.

COPPETE, Maria Conceição; FLEURI, Reinaldo Matias; STOLTZ, Tânia. Educação para a diversidade numa perspectiva intercultural. Revista Pedagógica, Chapecó, v. 14, n. 28, p. 231-62, 2012.

FLEURI, Reinaldo Matias. Educação intercultural no Brasil: a perspectiva epistemológica da complexidade. Revista Brasileira de Estudos Pedagógicos, Brasília, v. 80, n. 195, p. 277-89, maio/ago. 1999.

. Educação intercultural e movimentos sociais: considerações introdutórias. In: FLEURI, Reinaldo Matias (Org.). Intercultura e movimentos sociais. Florianópolis: Mover; NUP, 1998. p. 9-27.

FREIRE, Paulo. Pedagogia da autonomia: saberes necessários à prática educativa. 31. ed. São Paulo: Paz e Terra, 2007.

Educação como prática de liberdade. 24. ed. Rio de Janeiro: Paz e Terra, 2000.

GARCÍA, Carlos Marcelo. Formação de professores - para uma mudança educativa. Porto: Porto Editora, 1999.

GARTON, Laura; HARTHORNTHWAITE, Caroline; WELLMAN, Barry. Studying Online Social Networks. Journal of Computer Mediated Communication, V 3, issue 1 (1997). Disponível em: <http://www.ascusc.org/jcmc/vol3/issue1/garton.html>. Acesso em: 11 dez. 2017.

GATTI, Bernadete A.; BARRETO, Elba Siqueira de Sá. Professores no Brasil: impasses e desafios. Brasília: UNESCO, 2009.

GIMENO SACRISTÁN, J.; PÉREZ GÓMEZ, A. I. Compreender e transformar o ensino. Porto Alegre: Artes Médicas, 1998.

GIROUX, Henry. Escola crítica e política cultural. Tradução de Dagmar M. L. Zibas. São Paulo: Cortez; Autores Associados, 1987. (Coleção Polêmicas do Nosso Tempo, 20).

HINE, Christine.Virtual ethnography. London: SAGE Publications, 2000. 
IMBERNÓN, F. Formação docente e profissional: formar-se para a mudança e a incerteza. São Paulo: Cortez, 2010.

. Formação permanente do professorado: novas tendências. São Paulo: Cortez, 2009. . Formação docente e profissional: formar-se para a mudança e a incerteza. São Paulo: Cortez, 2004.

LÉVY, Pierre. Cibercultura. Tradução de Carlos Irineu da Costa. São Paulo: Editora 34, 1999.

LOPES, Maria Cristina Lima Paniago; SANTOS, Rosimeire Martins Régis dos. Conectividade e colaboração virtual em contexto multicultural. In: NASCIMENTO, Adir Casaro; LOPES, Maria Cristina Lima Paniago; BITTAR, Mariluce (Org.). Relações interculturais no contexto de inclusão. Campinas: Mercado de Letras, 2012. p. 147-66. (v. 1).

MARCELO GARCÍA, C. Formação de professores: para uma mudança educativa. Portugal: Porto, 1999.

MEDRADO, Adonai Estrela. Sujeitos em janelas: a relação com o saber na EAD. 131f. Dissertação (Mestrado em Educação e Contemporaneidade) - Universidade do Estado da Bahia, Salvador. 2012. Disponível em: <http://www.cdi.uneb.br/pdfs/educacao/2012/ adonai_estrela_medrado.pdf>. Acesso em: 11 dez. 2017.

MONTEIRO, Agostinho Reis. O direito à educação. Lisboa: Livros Horizontes, 1998.

NÓVOA, Antonio. Os professores e a sua formação. Lisboa: Publicações Dom Quixote, 1995a.

. Os professores e as histórias da sua vida. In: NóvOA, A. (Org.). Vidas de professores. Porto: Porto Editora, 1995b.

PACHECO, J. A. O pensamento e a acção do professor. Porto: Porto Editora, 1995.

PANIAGO, Maria Cristina Lima; SANTOS, Rosimeire Martins Régis; GODOI, Katia Alexandra. Interações, diálogos, acolhimentos e negociações em uma formação continuada intercultural: uma abordagem de cunho etnográfico virtual. In: MACIEL, Cristiano; ALONSO, Kátia Morosov; PANIAGO, Maria Cristina Lima (Org.). Educação a distância: Interação entre sujeitos, plataformas e recursos. Cuiabá: Edufmt, 2016, p. 389-415. (v. 1).

PRIMO, Alex. Avaliação em processos de educação problematizadora online. In: Marco Silva; Edméa Santos (Org.). Avaliação da aprendizagem em educação online. São Paulo: Loyola, 2006, p. 38-49. (v. 1).

RECUERO, Raquel. Redes sociais na internet. Porto Alegre: Sulina, 2009. Disponível em: <http://revistaseletronicas.pucrs.br/ojs/index.php/revistafamecos/article/ viewFile/8194/5883>. Acesso em: 17 fev. 2017. 
SANTINELLO, Jamile; VERSUTI, Andrea. Facebook conectividade e reflexões da rede social para o contexto social do século XXI. In: PORTO, C.; SANTOS, E. (Org.). Facebook e educação: publicar, curtir, compartilhar [online]. Campina Grande: EDUEPB, 2014. p. 185-97. Disponível em: <http://books.scielo.org>. Acesso em: 25 jan. 2017.

SANTOS, Edméa Oliveira; ROSSINI, Tatiana. Comunidade REA-Brasil no Facebook: um espaço de ativismo, autorias, compartilhamentos. In: PORTO, Cristiane; SANTOS, Edméa (Org.). Facebook e educação: publicar, curtir, compartilhar. Campina Grande: EDUEPB, 2014. p. 85-112: Disponível em: <http://static.scielo.org/scielobooks/c3h5q/pdf/ porto-9788578792831.pdf>. Acesso em: 19 fev. 2017.

TARDIF, Maurice; LESSARD, Claude. O trabalho docente: elementos para uma teoria da docência como profissão de interações humanas. Tradução de Lucy Magalhães. 4. ed. Petrópolis, RJ: Vozes, 2011.

THOMPSON, John Brookshire. A mídia e a modernidade: uma teoria social da mídia. Petrópolis: Vozes, 2013.

TORRES, Carlos Alberto. Democracy, education and muticulturalism - dillemas of citizenship in a global world. Lanham. Nova lorque: Oxford. Rowman; Littlefield Publ, 1998.

VIEIRA, Ricardo. Ser inter/multicultural. Jornal A página da educação. Portugal, ano 8, n. 78, mar. 1999. Disponível em: <http://www.a-pagina-da-educacao.pt/>. Acesso em: 2 dez. 2016.

\section{Sobre os autores:}

Rosimeire Martins Régis Santos: Pedagoga. Mestre e Doutora em Educação. Professora Universitária. Integrante do Grupo de estudos e pesquisas em Tecnologia Educacional e educação a distância (GETED) na Universidade Católica Dom Bosco. E-mail: profarosimeireregis@hotmail.com

Maria Cristina Lima Paniago: Graduação em Letras. Mestrado e Doutorado em Lingüística Aplicada e Estudos da Linguagem. Pesquisadora visitante da Universidade de Manitoba, Canadá (Estágio Pós-Doutoral) Department of Family Social Science - Faculty of Human Ecology. Atualmente é professora do Programa de Pós-Graduação em Educação Mestrado e Doutorado na Universidade Católica Dom Bosco (UCDB), e líder do Grupo de estudos e pesquisas em Tecnologia Educacional e educação a distância (GETED/UCDB). E-mail: cristina@ucdb.br

\section{Recebido em 10 de março de 2017}

Aprovado para publicação em 31 de março de 2017 
